\title{
К дискуссии о романизации кочевых племен североафриканских провинций Римской империи: сведения источников времени Антонинов*
}

\author{
Г.В. Усков \\ Ярославский государственный университет им. П.Г. Демидова, \\ Россия, 150003, Ярославль, ул. Советская, 14/2 \\ E-mail: ggu-03@mail.ru
}

\begin{abstract}
Аннотация. В антиковедении существует дискуссия о романизации, ее особенностях и допустимости применения этого понятия. В контексте этой дискуссии в статье рассматриваются отношения между римскими властями и кочевым населением североафриканских провинций в период принципата Антонинов. На основании данных эпиграфики и нарративных источников автор приходит к выводу, что по отношению к берберским племенам проводилась политика, сочетавшая, с одной стороны, невмешательство в жизнь основной массы племени, с другой стороны - романизацию элит кочевников. В некоторых случаях кочевников переселяли на другие места или их сезонные передвижения могли быть ограничены. Вместе с тем предпочтение в отношениях с кочевыми племенами отдавалось мирным способам решения конфликтов. Автор признает процесс романизации части племен и считает допустимым употребление понятия «романизация» применительно к Северной Африке. Однако утверждается, что под романизацией нельзя понимать лишь навязывание римских культурных норм или растворение африканской идентичности в общеимперской.
\end{abstract}

Ключевые слова: Римская империя, Антонины, провинции, Северная Африка, кочевники, империализм, романизация.

Для цитирования: Усков Г.В. 2020. К дискуссии о романизации кочевых племен североафриканских провинций Римской империи: сведения источников времени Антонинов. Via in tempore. История. Политология, 47 (3): 490-496. DOI 10.18413/2687-0967-2020-47-3-490-496.

\section{To the issue of romanization of nomadic tribes in the North African provinces of the Roman empire: sources of the period of Antonines*}

\author{
Grigory V. Uskov \\ Yaroslavl State University after P.G. Demidov, \\ 14/2 Sovietskaya St., Yaroslavl, 150003, Russia \\ E-mail: ggu-03@mail.ru
}

\begin{abstract}
There is a discussion in classical studies about romanization and acceptability of usage of this term. The article considers relationship between Roman authorities and nomadic population of the North African provinces during the period of Antonines in the context of this discussion. The author comes to the conclusion about a policy was pursued towards the Berber tribes combining noninterference in life of most part of the tribe and romanization of nomadic elites. In some cases nomads moved to other places or their seasonal movements could be limited. At the same time preference in
\end{abstract}

\footnotetext{
* Статья подготовлена при поддержке РФФИ, проект № 19-39-90030 «Межкультурный диалог в эпоху Античности (на примере североафриканских провинций Римской империи II в. н. э.)».

The reported study was funded by RFBR, project number 19-39-90030.
} 
relations with nomadic tribes was given to peaceful ways of resolving conflicts. The author acknowledges process of romanization of part of the tribes and considers it acceptable to use this concept in relation to North Africa. It is argued that romanization cannot be understood only as the imposition of Roman cultural norms or the dissolution of African identity in the general imperial. A person could have Roman citizenship and be loyal to princeps and the Roman empire, remaining a member of his tribe and preserving its cultural traditions.

Keywords: Roman Empire, Antonine dynasty, provinces, North Africa, nomads, imperialism, Romanization.

For citation: Uskov G.V. 2020. To the issue of romanization of nomadic tribes in the North African provinces of the Roman empire: sources of the period of Antonines. Via in tempore. History and political science, 47 (3): 490-496 (in Russian). DOI 10.18413/2687-0967-2020-47-3-490-496.

В историографии римской Северной Африки можно выделить три основные точки зрения на римскую систему управления провинциями и отношения властей с коренным населением. Первый подход, выработанный историками под влиянием событий эпохи колониализма, был характерен для трудов XIX и 1-й пол. XX вв. В рамках этого подхода исследователи подразумевали, что находившиеся на более низком уровне развития коренные жители Африки выступали либо в роли потребителей римской культуры, подвергаясь романизации (городское население и племенная знать), либо продолжали вести традиционный образ жизни. Р. Канья усматривал большую роль в поддержании римского контроля над Африкой непосредственно армии, так как она противостояла мятежам [Cagnat, 1909, p. 285]. Ш.-А. Жюльен полагал, что Рим опирался на местную романизованную элиту, чтобы, не заботясь о нуждах местного населения, проводить в своих интересах колонизацию региона [Жюльен, 1961, с. 194]. Соответственно, отношения между римлянами и коренными жителями региона изображались как враждебные, а существование кочевых племен представлялось угрозой римской власти, опиравшейся на городское население.

Второй подход можно назвать «антиколониальным», он формируется во время крушения колониальной системы в 50-х и 60-х гг. XX в. Если ранее взаимодействие Рима и Африки рассматривали лишь как привнесение на Черный континент более передовой римской культуры в рамках романизации региона, то теперь исследователи стали писать об обратном влиянии Африки на римскую культуру и африканском сопротивлении романизации [Courtois, 1955, p. 66; Benabou, 1976, p. 587]. Сторонники этой теории утверждали, что влияние римлян на африканцев если и имело место, то являлось крайне незначительным и поверхностным.

Наконец, третий подход начинает формироваться в 70-х гг. ХХ в. и может быть назван «компромиссным». В рамках данного подхода признается значительное культурное влияние римлян на африканцев, но вместе с тем не отрицается и обратное влияние, а также отмечается сохранение коренными жителями провинций своей африканской идентичности и самобытности. Появляется взгляд на Римскую империю как на совокупность различных типов обществ, сосуществовавших вместе [Shaw, 2008, p. 361]. Отношения между римлянами и африканцами, согласной этой концепции, скорее можно описать с позиций взаимовыгодного сотрудничества, а не постоянного противостояния и культурного соперничества. Ч.Р. Уиттэкер полагал, что система лимесов, существовавшая ко II веку, была нацелена на контроль над сезонными перемещениями кочевников, а не на оборону от них [Whittaker, 2008, p. 528]. Эта же точка зрения разделялась П. Хизером, который писал, что кочевники уходили в зимний период на юг в предпустынные районы. Когда же они иссушались к лету, племена возвращались на север в земледельческие области. Таким образом, полагал Хизер, римские солдаты и укрепления нужны были преимущественно для того, чтобы скот кочевников не вытаптывал посевы. В этих условиях, - писал исследователь, - римляне продолжали выгодно вести дела с кочевниками, что явно не подтвер- 
ждает тезис о враждебном характере отношений [Heather, 2006, p. 183]. Происходит переоценка самого понятия «романизация», которое перестает трактоваться как навязывание римской культуры. В определенных случаях, как акцентировал В. Ек, правильно говорить даже не о романизации, а о «самороманизации» (self-romanization) [Eck, 2008, p. 274]. Отмечается, что «двигателем» романизации скорее выступали конкурирующие местные элиты, а не римские власти [Whittaker, 2008, p. 544; Pichot, 210, p. 240].

На наш взгляд, именно этот подход является наиболее перспективным и уместным для описания взаимоотношений между коренными африканцами и римлянами. Сегодня этот подход встречается в большинстве научных трудов о Северной Африке. В то же время можно встретить и работы с традиционными «колониальными» оценками римского присутствия в Северной Африке [Бембай, 2017, с. 8-9].

Не менее важное значение в контексте данного вопроса имеет проблема римского империализма. Само понятие «империализм» первоначально, согласно британскому экономисту Д. Гобсону, обозначало новую стадию в развитии капиталистического общества. В узком смысле империалистической принято называть агрессивную политику великих держав в начале XX в., которая нашла логическое завершение в Первой мировой войне. В широком смысле под империализмом понимается внешняя политика, направленная на достижение политической, военной, экономической и культурной гегемонии. По определению французского историка Ж. Каркопино, под империализмом можно понимать способ народа думать и действовать, исходя из желания подчинить другие народы [Сarcopino 1961, р. 20]. Таким образом, истоки империализма как явления вполне можно усматривать в эпоху Древнего мира [Шишкин, 2017, с. 101].

Конечно, следует понимать разницу между античным империализмом, носившим преимущественно политический и военный характер, и империализмом начала XX в. Тем не менее, употребление термина «римский империализм» является вполне допустимым. Дискуссия о характере империалистической римской внешней политики берет свое начало в XIX в. А.Б. Егоровым было отмечено, что для работ XIX - 1-й пол. XX в. был характерен тезис о преимущественно положительном влиянии римлян на присоединенные к империи народы и позитивные оценки римского империализма с культурной и экономической точек зрения. Признавались негативные последствия римского завоевания, связанные с уничтожением населения, угоном его в рабство и экономическим разорением. Вместе с тем, римляне, писал российский антиковед, согласно этой концепции, принесли более развитую античную цивилизацию племенам Западной Европы, одновременно выступая преемниками греческой цивилизации на эллинистическом Востоке. Было создано единое культурное и экономическое пространство, положено начало современной европейской цивилизации.

Во 2-й пол. XX в. появились иные оценки римской внешней политики, рассматривавшие внешнюю и провинциальную политику Рима как агрессивную и захватническую. Более того, эта политика представлялась как не отвечавшая интересам самого же Рима [Егоров, 2006, с. 80].

В целом можно констатировать, что на сегодняшний день проблема римского империализма имеет выраженный научный интерес. На наш взгляд, представляется актуальным в контексте этой проблемы рассмотреть положение североафриканских кочевых племен и их отношения с римскими властями в эпоху Антонинов, которая считается периодом наивысшего расцвета Римской империи.

Можем ли мы усмотреть романизацию североафриканских кочевников или, по крайней мере, попытку таковой? Сама дискуссия о характере романизации и допустимости применения самого этого термина касается следующих аспектов:

1. Концепция романизации не учитывает этническое и культурное многообразие империи. В основном этот аргумент стал популярным среди антиковедов благодаря углубленному изучению истории отдельных провинций и развитию региональной 
археологии. Римская материальная культура, как полагают сторонники этой точки зрения, не тождественна римской идентичности.

2. Концепция романизации в ее старом виде не отражает в должной степени характер отношений между римлянами и местным населением, поскольку подразумевает одностороннее навязывание римской системы ценностей провинциалам. Намного правильнее было бы говорить о диалоге в процессе столкновении культур.

3. Концепция романизации подспудно признает наличие некоей общей идентичности в Римской империи, что является не вполне корректным [Whittaker, 2009, p. 200].

После присоединения Мавретанского царства в середине I в. н. э. Римская держава установила контроль над Северной Африкой. Подконтрольная римлянам территория при Антонинах делилась на три провинции - Проконсульскую Африку с административным центром в Карфагене, Цезарейскую Мавретанию с центром в Кесарии Мавретанской и Тингитанскую Мавретанию с центром в Тингисе. Наиболее развитой в экономическом плане являлась Проконсульская Африка. К Проконсульской Африке относились территории, которые были довольно развиты экономически еще до римского завоевания. В эту провинцию к началу правления Антонинов входила прибрежная полоса современной Триполитании, а также территории современных Туниса и Алжира (часть последнего). В состав провинции входила также и Нумидия - бывшая провинция Africa Nova, созданная Цезарем. Впоследствии Северы выделили Нумидию из Africa Proconsularis, превратив ее в отдельную провинцию. Границей между Африкой и Нумидией была линия к западу от города Гиппона-Регия. Западной границей Нумидии можно считать линию к западу от городов Куллу (совр. Колло) и Цирты (совр. Константина). К западу от Нумидии располагались Мавретания Цезарейская и Мавретания Тингитанская.

Вряд ли можно составить полный список племен, с которыми римлянам приходилось выстраивать отношении к началу II века. В I в. до н. э. Саллюстий писал, что не смог бы сообщить полностью достоверные сведения о всех племенах и народах Африки (Sall. Bell. Jug. 17). Из крупных этнических групп, проживавших в Африке, Саллюстием упоминаются ливийцы, мавретанцы, нумидийцы и гетулы и эфиопы (Sall. Bell. Jug. 19). Следует учитывать, что к I веку до н. э. Рим не контролировал основную часть североафриканского региона, соответственно, римские авторы не могли представить себе полную этническую картину населения этих земель.

Несколько меняется ситуация к концу I - началу II вв. Брент Шоу, опираясь на труды Плиния Старшего, например, писал о 516 народах и племенах только в Проконсульской Африке [Shaw, 2008, p. 381]. В эпиграфике II века упоминаются племена и племенные конфедерации, известные в I веке, например, племенной союз мусуламиев, участвовавший в восстании Такфарината (CIL VIII. $00270=$ CIL VIII. 11451 = CIL VIII. 23246 = AE 1907. 00017). Отмечается также существование довольно крупных племенных союзов субурбуров, нибгениев, бакватов и маккенитов (CIL VIII. 22787; AE 1942/43. 00068; CIL VIII. 21826).

Структура провинциального управления, выстроенная ко временам Антонинов в Африке, как и в целом во всей империи, была создана для решения следующих задач: обеспечение безопасности и контроля над местными племенами, своевременный сбор налогов, защита сельского хозяйства [Calsterer, 2008, p. 345]. В целом, большинство действий имперской администрации в период принципата Антонинов укладывается в эту логику.

Ко II веку активно распространяется практика переселения тех или иных племен на определенные участки границы. Нам известны примеры переселения племен нибгениев и субурбуров. Нибгении были размещены в районе к западу от Такапы и югу от Капсы, при этом городам была передана часть земель этого племени. Центром нибгениев стал город Цивитас Нибгениориум (CIL VIII. 22787). Известно, что после этого поселение получило статус civitas stipendaria [Brett, Fentress, 1996, p. 62]. При Траяне же было начато строительство дороги, соединившей город с Капсой. Наконец, при правлении Адриана городу был предоставлен статус муниципия. Несколько отличается ситуация с субурбурами. 
Первоначально местом проживания этого племени были пастбища рядом с современным городом Эль-Эулма (фр. Сен-Арно). Позднее племя было переселено в район современного Шотта (коммуна айн-Бейда, вилайет Уаргла). Вероятно, причиной послужили враждебные действия со стороны племени. Одна из надписей времен правления Коммода сообщает о восстановлении дороги после разорения племенем субурбуров (АЕ 1942/43. 00068).

В 137 г. прокуратор Мавретании Цезарейской Гай Петроний Целер занимался расселением нумидийцев, при этом указывалось, что земли племя получает по милости императора Адриана (Ex indulgentia Imp(eratoris) Caes(aris) Had/riani Aug(usti) fines / adsignati gen\{n\}ti Numidarum / per C(aium) Petroni/um Celerem / proc(uratorem) Aug(usti) pro(vinciae) / [M(auretaniae) C]aes[ariens(is) (CIL VIII. 08814) [Dalla Rossa, 2017, p. 198] Ч.Р. Уиттэкер полагал, что в некоторых случаях речь могла идти о политике расселения племен для формирования южных рубежей, которое в целом было закончено при Адриане [Whittaker, 2008, p. 304; Whittaker 2009, p. 197].

Нельзя не признавать, что Рим вряд ли пытался сделать носителями римских ценностей все коренное население Африки. Это было бы невозможно чисто с технической точки зрения. С другой стороны, у римских властей был такой инструмент как римское гражданство, дарование которого вождям кочевых племен активно практиковалось. В истории известно множество примеров использования теми или иными захватчиками определенных этнических групп или местной элиты в качестве опоры своей власти. Римская империя не была исключением. При этом получение римского гражданства не влекло потерю своей африканской идентичности. Акцент делался, прежде всего, на служении Империи и лично принцепсу, а также на добросовестном исполнении своих обязанностей. Показателен пример берберского вождя Лузия Квиета, сделавшего карьеру при Траяне. Говоря о личных качествах консуляра, античные авторы акцентируют внимание на доблести Квиета. Так, Кассий Дион сообщает, что ранее Квиет был удален со службы за недостойное поведение. Однако, когда Траяну понадобилась военная помощь мавров, Квиет по доброй воле явился к принцепсу и отличился в походах против даков многими подвигами. После этого вождь стал претором, а затем - консулом (Cass. Dio. LXVIII. 32.4). Можно найти в данной характеристике влияние Плиния Младшего, который в «Панегирике» писал о Траяне как о принцепсе, предпочитающем воздействовать на подданных не принуждением, а личным примером, обнаруживать и приближать наиболее достойных (Plyn. Pan. 13, 45). Иначе говоря, положительное воздействие римского мира и романизации превратило недисциплинированного варвара в полноправного члена гражданского коллектива, получившего признание принцепса и магистратуру консула. При этом Квиет ни в коем случае не порывал связи со своими соплеменниками, по всей видимости, сохраняя их до самой смерти [Bussi, 2006, p. 727]. Таким образом, включение в состав имперской элиты вождей кочевников активно практиковалось римскими властями.

Нельзя не сказать также и о практике назначения т. н. praefecti gentis, чиновников, призванных контролировать племена на территории Северной Африки. В основном они были римлянами, хотя во II веке известно не менее двух случаев, когда ими были назначены африканцы [Whittaker, 2009, p. 197]. При этом непосредственно вождю племени мог быть пожалован титул princeps gentis. Известно также, что во II веке был случай совмещения функций префекта и принцепса в Тубурсикум Нумидарум, где участие в городском самоуправлении и одновременно управлении соседним племенем нумидийцев принимал princeps Numidarum. Были и примеры, когда лица берберского происхождения могли становиться декурионами в городах [Машкин, 1951, с. 75].

Таким образом, во II в. римскими властями по отношению к кочевым племенам североафриканских провинций проводилась политика, сочетавшая, с одной стороны, невмешательство в жизнь основной массы племени, с другой стороны, целенаправленную романизацию элит кочевников. В некоторых случаях кочевников переселяли на другие места или их сезонные передвижения могли быть ограничены. 
Вместе с тем, предпочтение в отношениях с кочевыми племенами отдавалось мирным способам решения конфликтов. Это, на наш взгляд, способствовало тому, что в эпоху Антонинов отсутствовали крупные потрясения на территории североафриканских провинций. Соответственно, мы можем говорить о романизации части племен и считаем допустимым употребление самого этого понятия применительно к Северной Африке.

При этом под романизацией нельзя понимать лишь навязывание римских культурных норм или растворение африканской идентичности в общеимперской. Человек мог иметь римское гражданство, быть лояльным принцепсу и Империи, оставаясь членом своего племени и сохраняя его культурные традиции.

\section{Список литературы}

1. Бембай К. 2017. Римская политика в Африке в I-III вв. н. э. Диссертация на соискание ученой степени кандидата исторических наук. Белгород, 180.

2. Егоров А.Б. 2006. Последние планы Цезаря (к проблеме римского глобализма). Мнемон (5): 77-94.

3. Жюльен Ш.-А. 1961. История Северной Африки. Тунис, Алжир, Марокко. С древнейшего времени до арабского завоевания. Пер. с фр. М., Издательство иностранной литературы, 428.

4. Машкин Н.А. 1951. Из истории африканских городов во II-III вв. н. э. Вестник древней истории (2): 70-83.

5. Никишин В.О. 2017. Как культура преодолела негативный стереотип: портрет нумидийского царя Юбы II в контексте этнических предрассудков. Египет и сопредельные страны. Электронный журнал (2). URL: http://enc-journal.com/images/contributions/2017-2/2-1nikishin.pdf (дата обращения: 28 марта 2020).

6. Шишкин М.В. 2017. Теории империализма: особенности становления и развития. Вопросы политической экономии (1): 101-118.

7. Benabou M. 1976. La Resistance africaine a la romanisation. Paris, Librairie François Maspero, 634.

8. Brett M., Fentress E. 1996. The Berbers. Oxford, Blackwell, 282.

9. Bussi S. 2006. Lusio Quieto: un «maghrebino» ai vertici dell'Impero. L'Africa romana. Mobilità delle persone e dei popoli, dinamiche migratorie, emigrazioni ed immigrazioni nelle province occidentali dell'Impero romano XVI (2): 721-728.

10. Cagnat R. 1909 L'armee romain d'Afrique et l'occupation militaire de l'Afrique sous les impereurs. Paris, Imprimerie nationale, 513.

11.Calsterer H. 2008. Local and provincial institutions and government. In: The Cambridge Ancient History. Vol. XI. Cambridge, Cambridge University Press: 344-360.

12. Carcopino J. 1961. Les etapes de l'imperialisme romaine. Paris, Hachette, 272.

13. Courtois C. 1955. Les Vandales et l'Afrique. Paris, Arts et métiers graphiques, 166.

14. Dalla Rossa A. 2017. Les successeurs désignés du prince et leur patrimoine. À propos de la délimitation d'Er-Rahel en Maurétanie Césarienne (CIL VIII 21663). Cahiers du Centre Gustave Glotz. XXVIII: 197-212.

15. Eck W. 2008. Provincial administration and finance. In: The Cambridge Ancient History. Vol. XI. Cambridge, Cambridge University Press: 266-292.

16. Heather P. 2006. The Fall of the Roman Empire. London, Pan Books, 572.

17. Pichot A.2010. Les édifices de spectacle des Maurétanies romaines. Lausanne, Universite de Lausanne: $409 \mathrm{p}$.

18. Shaw B. Rebels and outsiders. In: The Cambridge Ancient History. Vol. XI. Cambridge, Cambridge University Press: 361-403.

19. Whittaker C.R. 2008. Africa. In: The Cambridge Ancient History. Vol. XI. Cambridge, Cambridge University Press: 514-546.

20. Whittaker C.R. 2008. Frontiers. In: The Cambridge Ancient History. Vol. XI. Cambridge, Cambridge University Press: 293-319.

21. Whittaker C.R. 2009. Ethnic discourses on the frontiers of Roman Africa. In: Ethnic Constructs in Antiquity. Amsterdam, Amsterdam University Press: 189-205. 


\section{References}

1. Bembay K, 2017. Rimskaya politika v Afrike v I-III vv. n. e. [Roman policy in Africa in the I - III centuries A. D.]. Belgorod, 180 (in Russian).

2. Egorov A.B. 2006. Poslednie plany Cezarya (k probleme rimskogo globalizma) [Last Caesar's plans (to the problem of Roman globalism)]. Mnemon (5): 77-94 (in Russian).

3. Julien Ch.-A. 1961. Istoria Severnoy Afriki. Tunis, Algir, Marocco. S drevneyshego vremeni do arabskogo zavoevania [Istoriya Severnoj Afriki. Tunis, Alzhir, Marokko. S drevnejshego vremeni do arabskogo zavoevaniya]. Moscow, Izdatelstvo inostrannoy literatury, 428.

4. Mashkin N.A. 1951. Iz istorii afrikanskih gorodov vo II-III vv. n. e. [From the history of African cities in the II-III A. D.]. Vestnik drevnej istorii [Journal of Ancient History] (2): 70-83 (in Russian).

5. Nikishin V.O. 2017. Kak kul'tura preodolela negativnyj stereotip: portret numidijskogo carya Yuby II v kontekste etnicheskih predrassudkov [How culture overcame a negative stereotype: a portrait of the Numidian king Juba II in the context of ethnic prejudice]. Egipet i sopredel'nye strany [Egypt and neighboring countries] (2). Available at: http://enc-journal.com/images/contributions/2017-2/2-1nikishin.pdf (accessed 28 March 20120) (in Russian).

6. Shiskin M.V. 2017. Teorii imperializma: osobennosti stanovleniya i razvitiya [Theories of imperialism: features of formation and development]. Voprosy politicheskoj ekonomii [Political Economy Issues] (1): 101-118 (in Russian).

7. Benabou M. 1976. La Resistance africaine a la romanisation. Paris, Librairie François Maspero, 634.

8. Brett M., Fentress E. 1996. The Berbers. Oxford, Blackwell, 282.

9. Bussi S. 2006. Lusio Quieto: un «maghrebino» ai vertici dell'Impero. L'Africa romana. Mobilità delle persone e dei popoli, dinamiche migratorie, emigrazioni ed immigrazioni nelle province occidentali dell'Impero romano XVI (2): 721-728.

10. Cagnat R. 1909 L'armee romain d'Afrique et l'occupation militaire de l'Afrique sous les impereurs. Paris, Imprimerie nationale, 513.

11. Calsterer H. 2008. Local and provincial institutions and government. In: The Cambridge Ancient History. Vol. XI. Cambridge, Cambridge University Press: 344-360.

12. Carcopino J. 1961. Les etapes de l'imperialisme romaine. Paris, Hachette, 272.

13. Courtois C. 1955. Les Vandales et l'Afrique. Paris, Arts et métiers graphiques, 166.

14. Dalla Rossa A. 2017. Les successeurs désignés du prince et leur patrimoine. À propos de la délimitation d'Er-Rahel en Maurétanie Césarienne (CIL VIII 21663). Cahiers du Centre Gustave Glotz. XXVIII: 197-212.

15. Eck W. 2008. Provincial administration and finance. In: The Cambridge Ancient History. Vol. XI. Cambridge, Cambridge University Press: 266-292.

16. Heather P. 2006. The Fall of the Roman Empire. London, Pan Books, 572.

17. Pichot A.2010. Les édifices de spectacle des Maurétanies romaines. Lausanne, Universite de Lausanne: 409 p.

18. Shaw B. Rebels and outsiders. In: The Cambridge Ancient History. Vol. XI. Cambridge, Cambridge University Press: 361-403.

19. Whittaker C.R. 2008. Africa. In: The Cambridge Ancient History. Vol. XI. Cambridge, Cambridge University Press: 514-546.

20. Whittaker C.R. 2008. Frontiers. In: The Cambridge Ancient History. Vol. XI. Cambridge, Cambridge University Press: 293-319.

21. Whittaker C.R. 2009. Ethnic discourses on the frontiers of Roman Africa. In: Ethnic Constructs in Antiquity. Amsterdam, Amsterdam University Press: 189-205.

\section{ИНФОРМАЦИЯ ОБ АВТОРЕ}

Усков Григорий Викторович, аспирант кафедры всеобщей истории Ярославского государственного университета им. П.Г. Демидова, Ярославль, Россия.

\section{INFORMATION ABOUT THE AUTHOR}

Grigory V. Uskov, post-graduate student of the Department of General History of the Yaroslavl Demidov State University, Yaroslavl, Russia. 